sion over Paris and a large tract of the country from the $4^{\text {th }}$ up to the 26th, without any intermission. Neither sun, nor stars, nor moon were visible for an instant during that lengthened period.

The prevailing opinion among meteorologists was that the nebulosity was formed by a mass of snow suspended in the atmo. sphere.

Although the notion was generally accepted, I opposed it, in my contributions to L'Electricité, remarking that if such were the case, snow or at least water should have fallen in Paris and vicinity where the dryness was complete from the apparition of this remarkable nebulosity. But being unable to settle the controversy without actual observation, I ascended in a balloon from La Villette Gas Works on January 25 at $2 \mathrm{~h}$. 35. p.m. I found my anticipations were quite correct, as not a single flake of snow was seen by me or by M. Anatole Brissonet, a young gentleman who was assisting me by manœuvring the balloon. But I was quite deceived in the thickness of the cloud, which did not exceed $3 \mathrm{co}$ metres, although it rendered the sun perfectly invisible, and I had written it ought to be numbered by thousands.

The earth was lost sight of gradually, and was perfectly invisible at 270 metres, but the sun was shining in all its glory at 580 metres, with blue sky. The cloud was not so blinding as usual when it is composed of condensed vapour, as the thermometer and barometer could be read with perfect accuracy in the centre of it, and the lower part of the balloon was entirely visible at a distance of about 4 or 5 metres, but the equator was lost in whitish smoke perfectlv impenetrable to sight. This nebulous matter appeared perfectly homogeneous, and I could see no trace of any crystalline matter, but an unexpected observation proved that it was formed of minute solidified atoms of water in a real microscopic state of division.

When we emerged from the cloud gently and slowly, I stop the throwing out of any ballast in order to remain in close vicinity of its surface. M. Brissonet and I observed carefully what was occurring around us. The heating effect of the sun was in some respect destroyed by the radiation towards the cloud, which was at a temperature of $5^{\circ} \mathrm{C}$. So we were floating at a level almost perfectly equal, in an air at a temperature from $-2^{\circ}$ to $-3^{\circ}$. The air at the surface of the clouds was perfectly calo, but at a few metres upwards it was moving north-north-easterly at a rate of eight miles an hour. The consequence was that we we were towed by the globe, and feeling keenly a cold current sweeping over our faces. We had uncriled our guide rope, the length of which was 60 metres, and the end of which was consequently immersed in the cloud and dragged into it. To our intense surprise, and I may say delight, we perceived that this part was quite loaded with hoar frost, which had precipitated regularly by series of hairs a few millimetres long. These accumulations during a sweep which lasted for an hour, and a distance of about eight miles, are consistent with the fact previously stated, that no deposit was visible during our ascent, which had been very slow indeed. My calculations show that our vertical velocity was not exceeding 30 metres per minute, which is only one-eighth of our horizontal velocity, continued during six times longer. In our descent, which was rather quicker, but not to a great degree, the sweeping may have accumulated the frost rime on the bottom of the car, which it could not have been easy to observe, and consequently I cannot state what occurred, but not a single crystal was deposited on our ropes during that period.

I have been unable to procure Scoresby's Sketches of the Polar Regions, but only a review by Arago, who says (ix p. 357, 10, tt seq.): The "frost-rime ou fumée-gelée est un phénomene particulier des ces regions de la terre ou le froid est de longue durée, dont une vapeur dense ${ }^{1}$ qui est dans un état complet de congelation. . . . Les parties extrémement deliées dont le frost-rime se compose s'attachent à tous les corps vers lesquels le vent les pousse, et y forment quelque fois une croûte de plus de 3 centimètres d'epaisseur, herisse de longues files pris. matiques, ou pyramidales la pointe dirigèe du côté du vent."

It seems to me that the constitution of cirrus clouds seems to be explained by these properties of frost-rime clouds. These minute crystals, which can remain for an indefinite period suspended in the air, are, properly speaking, the materies nivei, but not nives ipsa. It is by motion, either vertical or horizontal, that they are changed either into hoar-frost or snow, according to circumstances.

W. DE FONVIELLE

${ }^{2}$ I suppose that Scoresby is s?eaking of optical density

\section{Researches on Animals containing Chlorophyll}

Mr. PATRICK GedDes appears to have been anticipated in most of the points set forth in his paper on Further Researches on Animals containing Chlorophyll, published in NATURE of January 26 last, by Dr. Brandt, of Berlin, who, in a paper read before the Physiological Society of Berlin ton November II last, and published in the Proceedings of the Society on the "Symbiosis of Lower Animals with Algæ," describes the cultivation, after removal from the bodies of the various animals affected by them, of the well-known yellow and green chlorophyll-containing bodies, their development of starch grains, and their successfnl artificial implantation into the bodies of fresh hosts previously free from them; this latter being an important fact apparently not known to Mr. Geddes. Dr. Brandt further names the species of algæ in question under two genera, Zoochlorella and Zooxanthella, and gives to the peculiar physiological relations of mutual advantage between the plants and animals the term "symbiosis" Mr. Geddes appears not to have seen ihis paper of Dr. Brandt, since he merely refers to some of his earlier papers on the same subject, but it is important. Dr. Brandt's claims in the matter should not pass without notice in NATURE. I have not seen Dr. Brandt's original paper, but only an abstract published in the Naturforscher of January I4 last, from which I take the information given above.

H. N. MOSELEY

\section{The Movements of Jupiter's Atmosphere}

In NATURe, vol. xxv, p. 213, Mr. Darwin describes the bands on Jupiter as "due to the trades and anti-trades" set in $\mathrm{m}$ stion by the action of solar radiation on the solid body of the planet as are the trade-winds of the earth. Many other eminent astronomers still appear to accept this time-honoured explanation of the phenomena.

Have they reflected on the revelations supplied by the low specific gravity of Jupiter? There is no form of matter with which we are acquainted that could exist at a mean density of about one-fourth of that of the earth, while subject to the enormous pressure due to the mass of Jupiter, unless it were sufficiently hot to render the formation of a solid crust on its surface quite impossible. In order to attribute terrestrial solidity to either Jupiter, Saturn, Uranus, or Neptune we must invent a new kind of matter as infusible as platinum, and far lighter than hydrogen, or endow it with absolute incompressibility.

These planets, if composed of any of the chemical elements or compounds known to us, can only retain their low density under the enormous pressure of their masses by the agency of proportionately counteracting heat-repulsion. IAt and about their centres this may be so far overcome by the superincumbent pressure as to produce solid nuclei, but these must be very small in proportion to the mass of the planet.

Assuming the existence of such a central nucleus of Jupite surrounded by a great fluid envelope, how will it be affected by the gravitating reaction of the satellite, supposing the compres. sion to give it a specific gravity exceeding the mean specific gravity of its envelope?

It will obviously perform an eccentric rotation, or reeling, within the envelope. This motion must be very irregular and complex, owing to the different periods and the varying relative positions of the satellites; but the varying resultant of their gravitation forces will have one element of constancy, viz. a close coincidence with the plane of the planet's equator.

The effect of such internal reeling upon the surrounding gaseous mass explains far more efficiently than any possibility of solar radiation, the disturbances indicated by the ever changing belts and spots of this planet; and also the greater rotatory velocity of the equatorial spots, described by Mr. Denning in the above-named number of NATURE, p. 225

The correspondence of these with the varieties of rotation of the different parts of the solar surface observed by Carrington, is well worthy of note, and admit of similar explanation; planetary reaction in the case of the sun taking the place of the satellite reaction on Jupiter. In my essay on "The Fuel of the Sun" I have worked out other consequences of this reeling of the solar nucleus and their analogues in the greater planets.

Stoneb-idge Park, January 26 W. Mattieu Williams

\section{"The Lepidoptera of Ceylon"}

Mr. F. MOORE in no way betters the case against him by his letter printed in NATURE, vol. xxv. p. 79. The name of George 